\title{
The axonal cytoskeleton: from organization to function
}

\author{
Josta T. Kevenaar and Casper C. Hoogenraad* \\ Cell Biology, Faculty of Science, Utrecht University, Utrecht, Netherlands
}

The axon is the single long fiber that extends from the neuron and transmits electrical signals away from the cell body. The neuronal cytoskeleton, composed of microtubules (MTs), actin filaments and neurofilaments, is not only required for axon formation and axonal transport but also provides the structural basis for several specialized axonal structures, such as the axon initial segment (AIS) and presynaptic boutons. Emerging evidence suggest that the unique cytoskeleton organization in the axon is essential for its structure and integrity. In addition, the increasing number of neurodevelopmental and neurodegenerative diseases linked to defect in actin- and microtubule-dependent processes emphasizes the importance of a properly regulated cytoskeleton for normal axonal functioning. Here, we provide an overview of the current understanding of actin and microtubule organization within the axon and discuss models for the functional role of the cytoskeleton at specialized axonal structures.

Keywords: axon, cytoskeleton, actin, microtubule, kinesin, transport, presynapse, axon initial segment

\section{OPEN ACCESS}

Edited by:

Michael R. Kreutz,

Leibniz-Institute for Neurobiology,

Germany

Reviewed by:

Christian Gonzalez-Billault,

Universidad de Chile, Chile

Annie Andrieux,

Commissariat à l'Énergie Atomique et aux Énergies Alternatives, France

*Correspondence:

Casper C. Hoogenraad, Cell Biology, Faculty of Science, Utrecht University, Padualaan 8, 3584CH Utrecht, Netherlands c.hoogenraad@uu.nl

Received: 17 June 2015 Accepted: 31 July 2015 Published: 14 August 2015

Citation:

Kevenaar JT and Hoogenraad CC (2015) The axonal cytoskeleton: from organization to function.

Front. Mol. Neurosci. 8:44. doi: 10.3389/fnmol.2015.00044

\section{Introduction}

Neurons are the basic cells that process information within the brain. They are compartmentalized into two morphologically, molecularly and functionally distinct domains; the axonal and the somatodendritic compartments. Multiple short and highly branched dendrites function in receiving and integrating electrical synaptic inputs from thousands of neurons. In contrast, only a single axon is responsible for transmitting this integrated information in the form of an action potential, an electrical excitation wave that travels along the axonal membrane. To ensure that information is transmitted properly, the axon has a unique cytoskeletal organization and contains several specialized structures, including the axon initial segment (AIS) and presynaptic boutons (Figure 1).

The typical morphology and specialization of the axon is formed during a number of distinct developmental stages. Initially, neurons develop several short processes, called neurites. Then, upon neuronal polarization, one of these neurites grows longer than the others and becomes the axon, whereas the other neurites are destined to become the dendrites (Dotti et al., 1988). Axon specification is regarded as the fundamental process that gives the neuron its polarized morphology and segregates its neuronal functions into the somatodendritic and axonal compartments (Stiess and Bradke, 2011). Shortly after the initial specification of the axon, the AIS assembles through the local accumulation of specific proteins at the proximal part of the axon which starts around 4 days in culture and continues with 8 more days (Boiko et al., 2007; Hedstrom et al., 2007). Through the assembly of the AIS, the axon is separated from the rest of the neuron to maintain neuronal polarity (Leterrier and Dargent, 2014). Later on, numerous signaling molecules direct further axonal outgrowth, the formation of synaptic contacts and subsequently, presynaptic differentiation through the assembly of presynaptic protein complexes (Chia et al., 2013). 


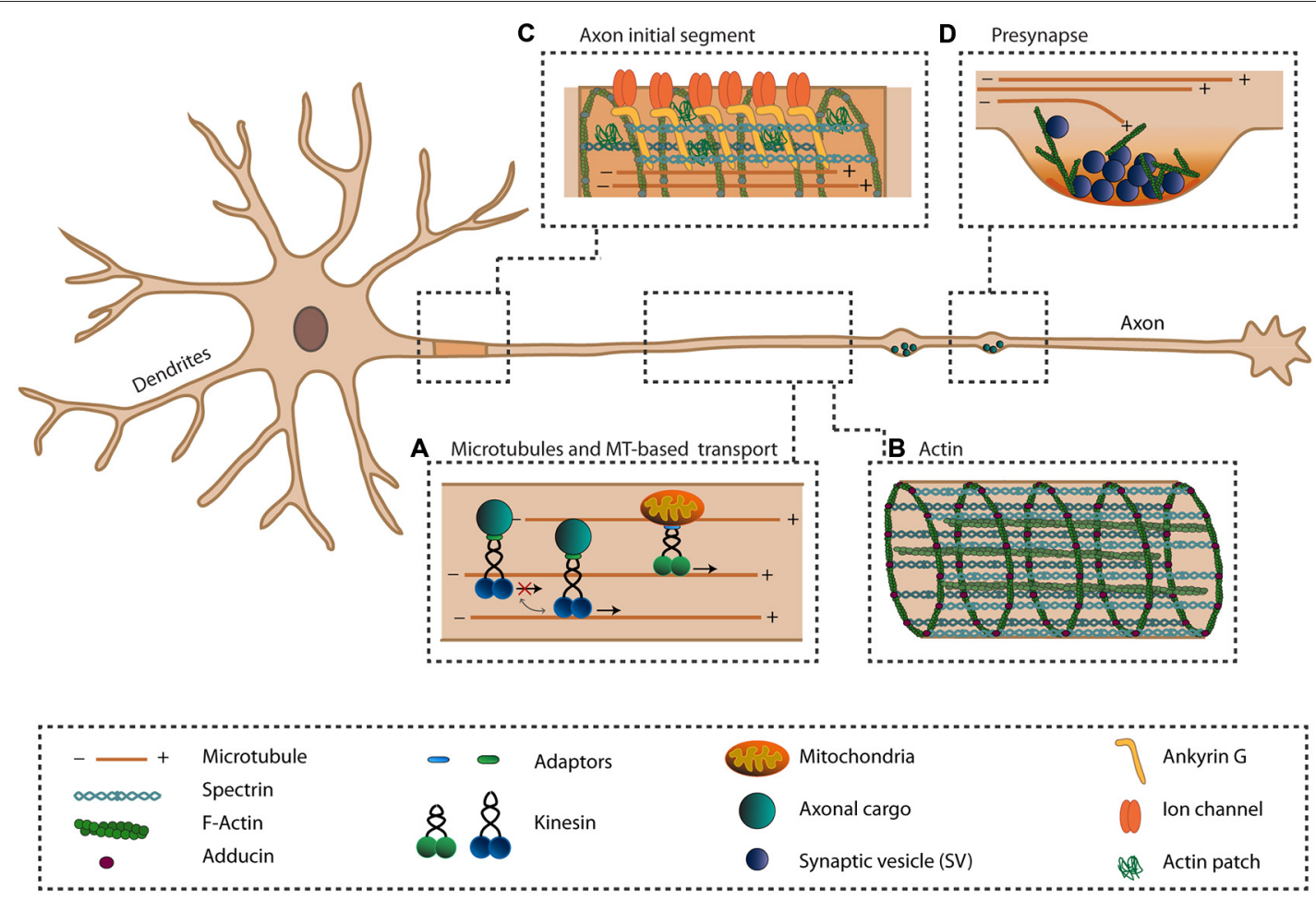

FIGURE 1 | The axonal cytoskeleton and axon-specific structures. The axon is specialized in transmitting information to other cells. To ensure this function, the axon has a unique cytoskeletal organization (A,B) and has several specialized structures (C,D). (A) The unique unipolar orientation of the microtubules (MTS) within the axon provides anterograde transports of various axonal cargoes via plus-end directed kinesins. Various mechanisms exist that regulate the activity of kinesins. (B) The actin cytoskeleton within the axon exists as periodically spaced rings underneath the axonal plasma membrane, organized by spectrin and adducing, and provides the axon with elastic and stable support. Along the axon, bundles of actin are present. (C) The axon initial segment (AIS) is important for the initiation of action potentials and maintaining neuronal polarization by acting as a transport filter. Within the AIS, a dense meshwork of cytoskeletal and scaffolding proteins exists where Ankyrin-G (AnkG) links transmembrane proteins to the actin and microtubule cytoskeleton. (D) At the presynaptic site, neurotransmitter-filled synaptic vesicles (SVs) are docked at the presynaptic membrane and undergo exocytosis upon the arrival of an action potential. Within the presynapse, actin is proposed to exist in a branched network where it may function in the controlling exo- and endocytosis, recruiting and positioning of SVs and organizing the active zone (AZ).
The neuronal cytoskeleton, which is composed of microtubules (MTs), actin filaments and neurofilaments, enacts important functions in both the establishment and maintenance of neuronal polarity, morphology and integrity of axons (Luo, 2002; Barnes and Polleux, 2009; Kapitein and Hoogenraad, 2011). The main function of neurofilaments, which are particularly abundant in axons, is to control the axon diameter and thereby axonal conductance (Yuan et al., 2012). MTs and actin filaments mainly affect axon specification and growth and provide the roads for longand short-range active axonal transport (Luo, 2002; Kapitein and Hoogenraad, 2011; Sainath and Gallo, 2015). Both MTs and actin filaments are dynamic structures, meaning that they continuously grow and shrink, which facilitates the continuous remodeling of the cytoskeleton. Already during the initial stages of neuronal development and neurite outgrowth, the cytoskeleton enacts an important role in generating intracellular forces and acts as a signaling device (Witte and Bradke, 2008). It is suggested that neurite initiation and outgrowth depends on the local increase in actin dynamics in combination with microtubule stabilization (Flynn et al., 2012). For example, during neuronal polarization, actin waves enhance the delivery of actin and actin-associated proteins to the putative axon which promotes axonal elongation (Flynn et al., 2009), which is mediated by the directional assembly and disassembly of membrane-anchored F-actin (Katsuno et al., 2015). In addition, kinesin-1 driven sliding of MTs may provide the force needed for initial neurite outgrowth (Lu et al., 2013). During the later processes of axonal outgrowth, microtubule and actin dynamics are critical for driving growth cone motility and axon guidance (Kolodkin and Tessier-Lavigne, 2011; Vitriol and Zheng, 2012; Gomez and Letourneau, 2014; Liu and Dwyer, 2014), but since excellent recent reviews already exist on this topic their role in these processes will not be discussed here. Finally, when contacts with other neurons are made, actin rearrangements play important roles in proper development of presynaptic sites through the organization of numerous presynaptic components (Cingolani and Goda, 2008; Nelson et al., 2013). 
Since MTs and actin filaments are involved in various stages of axon formation and outgrowth, they have recently received much attention in studies on axon regeneration. These studies are all aimed at increasing the regenerative properties of central nervous system (CNS) axons. This could be achieved by affecting cytoskeletal rearrangements directly (Gordon-Weeks and Fournier, 2014) or by increasing axonal transport of receptors that mediate growth by signaling onto the cytoskeleton in response to extracellular cues (Eva and Fawcett, 2014). For example, microtubule stabilization after injury has been shown to promote axon regeneration in vivo (Hellal et al., 2011). Also, a more recent study demonstrated the potency of the Food and Drug Administration (FDA) approved microtubule-stabilizing drug epothilione $\mathrm{B}$ in promoting axon growth and functional recovery after CNS injury in rodent spinal cords (Ruschel et al., 2015). In addition, the developmentally regulated exclusion of growth-related receptors from the axon is suggested to account for the lack of regenerative ability of mature CNS axons. This regenerative ability was demonstrated to be restored by altering axonal trafficking to reintroduce these growth-related proteins into the axon in vitro (Franssen et al., 2015). Moreover, kinesin-1 mediated microtubule sliding has also been demonstrated to be involved in axonal regeneration in Drosophila (Lu et al., 2015). Normally, microtubule sliding is developmentally down-regulated, but injury-induced calcium influx induces local microtubule disassembly and subsequently the formation of local microtubule arrays with mixed polarity (del Castillo et al., 2015; Lu et al., 2015). The formation of these mixed microtubule polarity arrays re-introduces the ability for kinesin-1 mediated microtubule sliding and thereby neurite outgrowth ( $\mathrm{Lu}$ et al., 2015). In general, severe cytoskeletal rearrangements occur after injury and targeted cytoskeletal rearrangement may be a promising strategy for enhancing axon regeneration.

In addition to axon regeneration, the axonal cytoskeleton has also gained much attention in respect to its association with several neurological diseases. For example, several developmental and neurological disorders have been described in which defects in axonal transport, outgrowth, targeting and synapse functioning are caused by disruption of axonal cytoskeleton-dependent processes (De Vos et al., 2008; Letourneau, 2009; Franker and Hoogenraad, 2013; Breuss and Keays, 2014). For example, the motor neuron degenerative disease Amyotrophic Lateral Sclerosis (ALS) has been associated with axonal cytoskeletal rearrangements and axonal transport dysfunction (Robberecht and Philips, 2013). In Alzheimer's disease (AD), dissociation and mis-sorting of the axonal microtubule-associated protein tau and cytoskeletal disruptions are linked to transport deficits and synaptic dysfunction (Zempel and Mandelkow, 2014). In addition, impaired regulation of microtubule stability, caused by spartin deficiency, is suggested to affect presynaptic development and axonal survival which underlies the neurodegenerative disease Troyer syndrome hereditary spastic paraplegia (HSP; Nahm et al., 2013). These neurological disorders emphasize the importance of a functional and properly regulated axonal cytoskeleton for normal axonal functioning. In this review, we will give an overview of specialized axonal structures and relate their specific functions to the unique organization of the axonal cytoskeleton.

\section{Actin and Microtubule Organization Within the Axon}

MTs are cylindrical polymers built up from $\alpha$ - and $\beta$ tubulin hetrodimers, with a fast-growing plus-end and a more stable minus-end. These tubulin polymers switch stochastically between polymerization and depolymerization, a process called dynamic instability (Mitchison and Kirschner, 1984). The dynamics of MTs are regulated by a large number of factors, including microtubule-associated proteins (MAPs), motor proteins, post-translational tubulin modifications and plus-end tracking proteins (Schuyler and Pellman, 2001; Dehmelt and Halpain, 2005; Akhmanova and Steinmetz, 2010; Janke and Kneussel, 2010; Drummond, 2011; Niwa, 2015). For example, various MAPs that decorate axonal MTs, including MAP1B and the axon-specific protein tau, influence microtubule dynamics by stabilization. (Cleveland et al., 1977; Drechsel et al., 1992; Tortosa et al., 2013; Derisbourg et al., 2015). In axons, MTs form an unique unipolar organization, where all MTs are oriented with their plus-end towards the axon tip, whereas in dendrites their orientation is mixed (Baas et al., 1988; Stepanova et al., 2003; Stone et al., 2008; Kapitein et al., 2010; Figure 1A). This unique orientation in the axon has important implications for its function, since it affects the specific sorting of axonal and dendritic cargos (Kapitein and Hoogenraad, 2011).

Actin filaments (F-actin), polymers built up from globular actin (G-actin), are polarized due to the orientation of each actin monomer in the filament. On the growing, barbed end, subunits are added while on the opposite side, the pointed end, monomers dissociate (Letourneau, 2009). Due to the weak interaction between these actin monomers, actin filaments rapidly shift between polymerization and depolymerization states. Actin dynamics is regulated by numerous actin-binding proteins (ABPs) via various mechanisms. For instance, ABPs can act by sequestering G-actin, nucleating actin filaments, capping or binding the barbed or pointed end to inhibit or promote polymerization or depolymerization respectively, severing of actin filaments, bundling, crosslinking, stabilizing, and anchoring of F-actin to other cellular components (Letourneau, 2009). F-actin is important for organizing the plasma membrane and for providing a cortical scaffold for the localization of protein complexes (Letourneau, 2009). In synapses, for example, stable F-actin plays a scaffolding role while rapid reorganization of actin remodels the synaptic structure during neuronal plasticity (Cingolani and Goda, 2008). Due to its difficulty to visualize, the organization of axonal actin has been more challenging to characterize precisely. For long, actin was assumed to exist only in a subaxolemmal space that contains a dense network of thin actin filaments, which connect the plasma membrane to the central microtubule cytoskeletal network (Hirokawa, 1982). Using electron microscopy techniques, patches of branched actin filaments, organized in the form of meshworks, have been 
identified along the axon. Distally, these patches contribute to the formation of axonal filopodia (Korobova and Svitkina, 2010; Spillane et al., 2011; Jones et al., 2014), which give rise to axonal collateral branches (Gallo, 2011). More recently, using super-resolution microscopy, axonal actin was found to be organized in regularly spaced rings that wrapped around the axon beneath the plasma membrane which are spaced and connected by spectrin (Xu et al., 2013; Lukinavičius et al., 2014). These ring-like structures along the axon arise already during axon specification and are formed by short actin filaments that are capped by adducin and are connected by spectrin tetramers that create a periodicity of $\sim 180-190 \mathrm{~nm}$ between the rings (Xu et al., 2013; D'Este et al., 2015; Figure 1B). This periodic sub-membrane lattice structure is suggested to provide elastic and stable mechanical support and to organize the molecular organization of the axonal membrane (Xu et al., 2013; D'Este et al., 2015). Besides the subcortical actin organization, bundles of actin are present along the axon where their abundance is highly dependent on the developmental stage (D'Este et al., 2015; Figure 1B). Likely, these actin bundles represent a more dynamic axonal F-actin population as was recently observed using live-cell imaging (Ganguly et al., 2015). Here, trails of actin are suggested to nucleate from specific sites along the axon, likely from the surface of stationary endosomes. These dynamic axonal F-actin filaments were found to be formin, but not Arp2/3, dependent and allow for the rapid availability of actin within the axon (Ganguly et al., 2015). This suggests a dual population of axonal actin, with on the axonal plasma membrane the more stable actin rings, providing mechanical support, and the dynamic inta-axonal actin filaments, providing flexibility needed for maintaining axonal and synaptic plasticity (Ganguly et al., 2015).

\section{The Role of the Axonal Cytoskeleton at the Axon Initial Segment}

One of the unique features of the axon is AIS, localized at the proximal part of the axon. The AIS is rich in ionchannels, scaffolding proteins, cellular adhesion molecules and cytoskeletal proteins, and is essential for the initiation of action potentials and thereby proper functioning of axon (Lai and Jan, 2006; Ogawa and Rasband, 2008). In addition, the AIS plays a key role in maintaining the axonal identity through its specialized cytoskeletal organization, by acting as a diffusion barrier to restrict proteins and lipids to either the axonal or somatodendritic compartment and by acting as a filter for active transport to prevent dendritic cargoes from entering the axon (Leterrier and Dargent, 2014; Yoshimura and Rasband, 2014). Recently, experiments using live-cell imaging of various neuronal cargoes demonstrated that dendritic cargoes abruptly stopped entering the axon, while axonal vesicles passed through the AIS without impediment, further supporting the notion that the AIS functions in actively selecting cargoes (Petersen et al., 2014). This barrier function is supported by a highly specialized protein network localized at the AIS. Here, the scaffolding protein Ankyrin-G (AnkG) links transmembrane proteins and $\beta I V$-spectrin to the actin and microtubule cytoskeleton (Grubb and Burrone, 2010; Rasband, 2010; Bennett and Lorenzo, 2013).
Together, scaffolding and cytoskeletal proteins set up a dense meshwork underneath the plasma membrane that is essential to build up and maintain a functional AIS (Jones et al., 2014; Figure 1C).

Within the AIS, cytosolic actin has been identified to exist in small networks, very similar to the actin patches observed in the more distal axon segments (Watanabe et al., 2012; D'Este et al., 2015), where individual filaments are thought to be oriented with their plus-end directed towards the cell body (Watanabe et al., 2012). Recent EM experiments demonstrated that actin filaments are rather sparse within the AIS and exhibit no polarized orientation within the AIS (Jones et al., 2014). Regardless of the precise organization of the actin filaments, the presence of actin patches may argue for a model where the AIS functions as a selective transport filter. It has been demonstrated that dendritic cargoes enter both the dendrites and the axon with similar frequencies, but hold their trafficking within the AIS in an actin-dependent manner. In this model, cargoes that have active myosin motors attached are excluded from entering the axon by anchoring to the actin patches (Al-Bassam et al., 2012). The view that actin has a critical function in the AIS is further supported by findings where disruption of the actin filter causes loss of polarized transport of axonal and dendritic cargoes (Winckler et al., 1999; Song et al., 2009). However, most dendritic cargoes have already stopped at the proximal region of the axon, and do not move into the AIS (Nakada et al., 2003; Song et al., 2009). Moreover, polarized transport was observed shortly after axon specification, even before AIS assembly and thus before the appearance of an actin meshwork at the AIS (Petersen et al., 2014). Therefore, these findings question the model of an actin-dependent selective cargo transport filter but may suggest an alternative function for actin patches at the AIS. Since the actin patches co-localize with presynaptic proteins (D'Este et al., 2015), one recent model suggests that they are axonal scaffold sites and play a role in supporting presynaptic boutons (Sankaranarayanan et al., 2003; Waites et al., 2011).

Besides actin, a role of MTs has also been proposed for the AIS filter and for the assembly of the AIS. During neuronal polarization, the first distinct feature of the proximal axon is microtubule bundling. Recently, using electron microscopy techniques, it has been demonstrated that this dense network of microtubule bundles arises even before the assembly of major AIS proteins, including AnkG (Jones et al., 2014). Later, the microtubule bundles acquire an AIS-specific submembranous dense coat that contains a network of various AIS proteins (Jones et al., 2014). The microtubule plus-end binding proteins EB1 and EB3 were identified as proteins that could link MTs to AnkG and stabilize the microtubule lattice in the AIS (Leterrier et al., 2011). Thus, the specialized organization at the AIS physically links AnkG to microtubule bundles and $\beta I V$-spectrin to cortical actin, which provides a strong structural basis for the AIS-dependent filter (Figure 1C).

\section{The Role of Presynaptic Actin}

Other unique, highly specialized structures within the axon are the presynaptic sites, which are essential for transmitting 
information to the connecting neuron. Together with the postsynapse of the receiving neuron, they form the sites where the actual communication between neurons takes place (Sudhof, 2004). The release of neurotransmitters is a critical step in the initiation of synaptic transmission. Neurotransmitter release is caused by exocytosis of synaptic vesicles (SVs) at the presynaptic active zone (AZ), triggered by the arrival of an action potential. At the AZ, the SV cycle underlies the regulated release of neurotransmitters and includes the recruitment, docking and priming of SVs at the presynaptic plasma membrane. This is followed by calcium-triggered exocytosis and subsequent endocytosis of the SV membrane, and concluded by recycling to replenish the SV pool and to sustain the vesicle cycle (Chua et al., 2010; Gundelfinger and Fejtova, 2012; Südhof, 2012). These various functions are executed by several overlapping sets of molecular machineries, which are dynamically assembled into a core macromolecular scaffold within the AZ (Chua, 2014).

Actin was originally thought to be involved in the assembly and development of the presynaptic sites (Zhang and Benson, 2001; Nelson et al., 2013). Findings in C. elegans and Drosophila indicate a key function of F-actin assembly in the initial stages of synaptogenesis (Chia et al., 2012, 2014; Koch et al., 2014). Actin dynamics, mediated by the Arp $2 / 3$ complex, have been shown to be critical for synapse formation in flies (Koch et al., 2014). In C. elegans, local F-actin rearrangements, triggered by the interaction of the synaptic cell adhesion molecules SYG-1 and SYG-2, are important for the subsequent recruitment and assembly of $\mathrm{AZ}$ proteins, including SYD-2/liprin- $\alpha$, via the actin-interacting protein NAB-1 (Chia et al., 2012, 2014). The angled geometry of the heterophilic SYG-1/SYG-2 complex was demonstrated to account for its synaptogenic properties, while rigidity of the adhesive complex allows close packing of SYG proteins, facilitating downstream signaling to the presynaptic cytoskeleton in C.elegans (Özkan et al., 2014). Since even poly-Dlysine-coated beads are able to induce presynaptic differentiation and local assembly of F-actin in vitro, it is suggested that cell adhesion by itself may be sufficient to induce F-actin assembly (Lucido et al., 2009), indicating the importance of celladhesion molecules in specifying the subcellular location of Factin rearrangements. This is consistent with the emerging idea that various cell adhesion molecules often converge on a similar pathway that induces F-actin rearrangements (Nelson et al., 2013; Chua, 2014), which could ultimately lead to the capturing of SV proteins (Bury and Sabo, 2014) and thereby presynaptic assembly.

However, the notion of a role for actin in regulating presynaptic function in mature neurons is emerging (Rust and Maritzen, 2015). Actin is highly concentrated at synapses, and it was recently shown that axonal actin patches are localized to presynaptic sites and that F-actin accumulations become even more prominent when the neuron matures (D'Este et al., 2015). The formin-dependent dynamic F-actin filaments within the axon described earlier, is suggested to provide the delivery of F-actin to synapses, as attenuation of these actin trails by inhibition of formin decreases F-actin delivery to and intensity within presynaptic sites (Ganguly et al., 2015). However, within the presynaptic sites, actin is suggested to mainly exist in an Arp2/3-dependent branched network (Korobova and Svitkina, 2010; Figure 1D). Synaptic actin becomes even more enriched upon synaptic activity, suggesting additional recruitment and polymerization of actin at the presynapse (Sankaranarayanan et al., 2003). Despite its high abundance in mature synapses, the exact role of actin at the presynaptic site is currently ambiguous (Cingolani and Goda, 2008; Rust and Maritzen, 2015). Several roles have been suggested, such as a solely structural function, a role in recruiting and positioning of SVs, in regulating exocytosis or in controlling endocytosis (Halpain, 2003; Rust and Maritzen, 2015). In knock-out mice of the actin-depolymerizing proteins $\mathrm{ADF} /$ cofilin, the impairment of actin dynamics causes reduced SV recruitment to the AZ (Wolf et al., 2014). Here, actin may function in the recruitment and positioning of SVs by acting as a scaffold for the clustering of SVs via synapsin. Alternatively, actin may also provide the tracks that allow SV transport via actinbased motor proteins to the AZ or could be involved in finetuning the localization of SVs after endocytosis (Dillon and Goda, 2005; Cingolani and Goda, 2008; Rust and Maritzen, 2015). For long, it has been thought that actin could function as a barrier at the presynaptic membrane to control SV exocytosis (Dillon and Goda, 2005). However, this idea has been challenged by recent findings where increased $\mathrm{F}$-actin levels, due to the absence of specific actin-depolymerizing proteins, led to increased exocytosis of SVs in mice (Wolf et al., 2014). Instead, this suggests that normal F-actin dynamics are essential for proper SV exocytosis (Rust and Maritzen, 2015), which could be, at least partially, mediated by the activity-dependent F-actin assembly function of the AZ protein Piccolo (Waites et al., 2011; Wagh et al., 2015). Defects in actin function or dysregulation of synaptic actin are also implicated in several mental disorders (Bernstein et al., 2011). Moreover, altered synapse development and morphology has been observed in a mouse model for Fragile $\mathrm{X}$ syndrome. These defects are presumably caused by dysregulation of actin dynamics, as altered levels of several actin-regulating proteins were observed (Klemmer et al., 2011). Moreover, mutant $\alpha$-synuclein, associated with familial Parkinson's disease (PD), was demonstrated to alter the rate of actin polymerization and to disrupt the actin cytoskeleton in vitro (Sousa et al., 2009).

Although actin has been regarded as the main cytoskeletal element within presynaptic sites, a possible role for MTs should also be noted (Figure 1D). Recently, the homolog of the microtubule stabilizing and bundling protein MAP1, Futsch, was demonstrated to localize to the neuromuscular junction (NMJ) terminals, where it regulates neurotransmitter release and AZ density in Drosophila (Lepicard et al., 2014). Here, Futsch localizes in between the AZ and MTs and thereby possibly links these two structures. Futsch might act in stabilizing and maintaining presynapse composition by reinforcing the interaction with the underlying microtubule cytoskeleton. In addition, microtubule reorganization via Futsch was demonstrated to be important in the activity-dependent remodeling of the AZ in Drosophila (Sugie et al., 2015). Prolonged exposure to environmental stimuli removes liprin- $\alpha$, RIM-binding protein DRBP and Bruchpilot (Brp) from the AZ in sensory neurons, but not SYD-1 or $\mathrm{Ca}^{2+}$-channel Cacophopny 
(Cac). This altered localization of AZ components is suggested to occur via the divergent canonical Wnt signaling pathway, which affects presynaptic microtubule stabilization through phosphorylation of Futsch (Sugie et al., 2015). Moreover, it has been reported that during synapse remodeling, microtubule dynamic increases which is required for proper kinesin-1 mediated axonal transport of synaptic components (Kurup et al., 2015). Likewise, mammalian MAP1 has also been implicated in regulating the distribution of AZ components. Both MAP1A light chain 2 (MAP1A-LC2) and MAP1B-LC1 are reported to link $\mathrm{N}$-type calcium channels to the actin cytoskeleton within the presynaptic site and to affect their degradation (Leenders et al., 2008; Gandini et al., 2014). More recently, MAP1B-LC1 was also found to interact with the presynaptic immunoglobulin protein KIRREL3 (Liu et al., 2015). These findings could establish exciting future research into the role of MTs in the organization and function of presynaptic sites.

\section{The Function of the Cytoskeleton in Axon Branching}

The formation of axonal branches relies heavily on cytoskeleton rearrangements. Actin assembly initiates filopodia formation, whereas subsequent microtubule invasion is important for stabilizing the branch (Gentil and Cooper, 2012; Kalil and Dent, 2014). For example, disruption of F-actin dynamics in neurons leads to a loss of axonal branching in vitro and in vivo, while elongation of the axon remains unaffected (Dent and Kalil, 2001; Spillane et al., 2011). Since synapses are often present at axonal branch points, it is suggested that synapse formation might promote the development of axonal branches (Vaughn, 1989). Consistently, synapse and axonal branch formation was found to often occur simultaneously in zebrafish developing retinal ganglion cell (RGC) axons, linking these two processes (Meyer and Smith, 2006). More recently, a common molecular pathway that links synapse formation to branching was described in C. elegans (Chia et al., 2014). Here, the interaction of the cell adhesion molecules SYG1/2 initiates axon branching, besides initiating presynapse assembly as described before Chia et al. (2014). SYG-1 recruits the WVE-1/WAVE regulatory complex (WRC), an activator of the Arp2/3 complex, to synapses. This triggers assembly of an axonal F-actin patch required for both synapse assembly and axonal arborization (Chia et al., 2014). MTs that invade axonal filopodia show a high degree of debundling and seem to interact with F-actin (Ketschek et al., 2015). This microtubule debundling might promote the ability of MTs to target filopodia (Ketschek et al., 2015). Branch formation is promoted by nerve growth factor (NGF), which acts on the microtubule cytoskeleton and promotes the localized debundling of MTs along the axon (Ketschek et al., 2015).

\section{Axonal Transport}

Besides its role in regulating and maintaining axonal polarization, outgrowth and stabilization, the axonal cytoskeleton also plays an essential role in active transport of axonal proteins, vesicles and organelles throughout the axon. Since the axon is functionally completely different from the dendrites, it requires a different set of proteins and cellular organelles. Active motor protein-driven transport is essential for sorting these axonal cargoes and to ensure that the correct proteins end up at the correct location within the cell (Kapitein and Hoogenraad, 2011). Active transport is especially important in axons, due to their significant length.

Three classes of motor proteins, kinesins, dyneins and myosins, transport cargoes along the cytoskeleton. Myosin moves specifically along actin filaments and is generally involved in contractile forces and short-range transport, while kinesin and dynein move along the microtubule cytoskeleton to facilitate long-range transport (Vale, 2003). Kinesin and dynein move in opposite directions: dynein moves towards the minusend of MTs, whereas most kinesins move towards the plusend (Hirokawa et al., 2010). Due to the unique microtubule organization in axons, kinesins are therefore responsible for the anterograde transport of axonal proteins while dynein enables retrograde transport (Kapitein and Hoogenraad, 2011; Figure 1A). Despite the broad variety of motor proteins, they share several general features. All motor proteins contain a relatively highly conserved motor domain, which associates with the cytoskeleton and binds ATP, needed for the generation of energy for movement. Motor proteins have a more diverse tail region, which associates with the cargo and contains several elements for regulation (Vale, 2003; Hirokawa et al., 2010). The diversity of the tail domain across various motor proteins allows for the ability of different motors to bind specific cargoes, whereby adaptor proteins further assist in establishing correct cargo-motor protein associations (Hirokawa and Takemura, 2005; Schlager and Hoogenraad, 2009).

Axonal transport is essential for the distribution of vesicles, organelles and signaling molecules along the axon to control polarization, axon elongation, and synapse function (Schlager and Hoogenraad, 2009; Chia et al., 2013; Maeder et al., 2014). A large proportion of these axonal cargoes is destined for the presynapse and needs to be delivered to these specialized sites through active transport (Goldstein et al., 2008; Hirokawa et al., 2010; Figure 1A). It has been suggested that several AZ proteins, including bassoon, piccolo and ELKS, are trafficked as preassembled complexes, whereas SV proteins and a distinct set of $\mathrm{AZ}$ proteins are transported by other types of vesicles (Shapira et al., 2003; Maas et al., 2012). However, this notion has become questionable since $\mathrm{SV}$ proteins and $\mathrm{AZ}$ proteins were reported to be co-trafficked, likely via heterogeneous multi-vesicle transport complexes (Tao-Cheng, 2007; Bury and Sabo, 2011; Wu et al., 2013).

Due to the heterogeneity of these vesicles and potential cotrafficking of various cargoes (Wu et al., 2013), the mechanism underlying active transport of these various synaptic components is not completely understood. It is known that anterograde transport of SV precursors is dependent on kinesin-3 family motors KIF1A and KIF1B $\beta$ (Hall and Hedgecock, 1991; Okada et al., 1995; Kondo et al., 2012) via adaptor proteins like DENN/MADD or liprin- $\alpha$ (Hall and Hedgecock, 1991; Okada et al., 1995; Shin et al., 2003; Miller et al., 2005; Niwa et al., 2008). Another kinesin motor, KIF5, has also been linked to the transport of synaptic components. It is suggested that KIF5 specifically transports proteins destined for the presynaptic 
membrane, including syntaxin via the adaptor syntabulin, and SNAP25 (Diefenbach et al., 2002; Su et al., 2004; Cai et al., 2007; Goldstein et al., 2008; Niwa et al., 2008; Morton et al., 2010). Besides synaptic components, other proteins and organelles are also actively transported along the axon. Amyloid precursor protein (APP) vesicles and dense core vesicles (DCV), containing the neurotrophic factor brain-derived neurotrophic factor (BDNF), are both trafficked via KIF5 via the adaptor JIP1 and Huntington, respectively (Kamal et al., 2000; Colin et al., 2008; Lo et al., 2011; Fu and Holzbaur, 2013). The latter can also be trafficked by KIF1A (Lo et al., 2011). Mitochondria are transported by KIF5 (Tanaka et al., 1998; Pilling et al., 2006; Campbell et al., 2014) via the adaptors Miro1/2-TRAK1/2, syntabulin, RanBP2 or FEZ1 (Cai et al., 2005; Fransson et al., 2006; Fujita et al., 2007; Brickley and Stephenson, 2011; Patil et al., 2013; van Spronsen et al., 2013; Babic et al., 2015). There are also indications that other kinesins contribute to mitochondrial transport within the axon, including KIF1B $\alpha$ (Nangaku et al., 1994) and Kinesin-like protein 6 (KLP6; Tanaka et al., 2011), to provide the synapses with the energy needed to meet their metabolic demand and to change synaptic energy levels and thereby synaptic activity (Sun et al., 2013).

Since most of the cargoes destined for the axon are made in the cell body, the axon needs to make use of some kind of mechanism that ensures that these cargoes are equally distributed throughout the axon and do not only accumulate at the most proximal sites. To overcome this challenge, a model is proposed in which inefficient capture of cargoes at synaptic sites and back-and-forth movements of cargoes enable cargoes to target synapses equally (Wong et al., 2012). This may be achieved by bidirectional or stop-and-go transport and by having reversible interactions of motor-cargo complexes with presynaptic sites. This view is supported by a biophysical model which suggests that a more democratic distribution of cargoes along the axon can indeed be achieved by making the transport process less efficient (Bressloff and Levien, 2015), implying that the activity and motility of kinesins needs to be correctly regulated to ensure proper cargo transport and delivery along the axon (Figure 1A).

The regulation of kinesin activity exists both at the level of kinesin-microtubule interactions and at the level of kinesin-cargo interactions. Distinct post-translational modifications of MTs are able to directly modulate the activity of specific kinesins, while leaving other kinesins unaffected (Janke and Bulinski, 2011; Song and Brady, 2015). Furthermore, MAPs are known to regulate transport by modulating the interaction of motors with the MTs (Vershinin et al., 2007; Dixit et al., 2008). In addition, the nucleotide-state of tubulin is suggested to affect the interaction of specific kinesins with MTs, thereby directing polarized transport due to the relative abundance of GTP-loaded MTs in the proximal part of the axon (Nakata et al., 2011; Morikawa et al., 2015). In addition to microtubule modifications, the organization and spacing of MTs affects kinesin motility (Conway et al., 2014; Wortman et al., 2014; Stephan et al., 2015), whereas the dynamics of the MTs may influences the kinesinmicrotubule interaction (Kurup et al., 2015). At the level of kinesin-cargo interactions, adaptor proteins direct the coupling of the cargo to the motor protein and function as a modulator of kinesin activity and motility (Akhmanova and Hammer, 2010; Maday et al., 2014). In addition to adaptor proteins, other mechanisms known to regulate cargo-motor associations include local $\mathrm{Ca}^{2+}$ concentrations, phosphorylation of kinesin motors and Rab-GTPase activity (Schlager and Hoogenraad, 2009). Besides these more subtle regulatory mechanisms of kinesin activity, kinesins can also be completely inhibited by the mechanism of autoinhibition. Here, the kinesin folds back on itself, enabling the tail-domain to bind and inhibit its own motor-domain (Verhey and Hammond, 2009). Although this mechanism is best described for kinesin-1 motor KIF5 (Verhey et al., 1998; Kaan et al., 2011), members of other kinesin families including KIF1A (Lee et al., 2004; Hammond et al., 2009), KIF17 (Hammond et al., 2010) KIF13B (Yamada et al., 2007), KIF21A (van der Vaart et al., 2013) and KIF16B (Farkhondeh et al., 2015) are also known to be regulated by autoinhibition. This inhibition can be released, and thereby regulated, by cargo binding or phosphorylation of the kinesin (Verhey and Hammond, 2009).

Impairments in axonal transport, caused by dysfunctioning or dysregulation of motor proteins, regulatory proteins or the underlying cytoskeleton could all have severe consequences for axonal functioning (Tischfield et al., 2011; Millecamps and Julien, 2013; Niwa et al., 2013; Encalada and Goldstein, 2014). Indeed, an increasing amount of neurodegenerative disorders is linked to abnormalities in transport-related proteins (De Vos et al., 2008; Hirokawa et al., 2010). For example, mutations in KIF5A have been linked to HSP and Charot-Marie-Tooth disease type 2 (CMT2; Liu et al., 2014). Likewise, mutations in the microtubule growth inhibiting kinesin KIF21A contribute to congenital fibrosis of the extraocular muscles type 1 (CFEOM1; Yamada et al., 2003), due to loss of autoinhibition of the microtubule growth inhibitor KIF21A (Cheng et al., 2014). These are only one of the few examples of the many transport-related neurological disorders, highlighting the importance of correct axonal transport functioning and regulation for proper axonal function.

\section{Conclusions and Outlook}

The axon is unique in its morphology and function and it contains several specialized structures and mechanisms that ensure proper axonal functioning. Here, we focused on the cytoskeletal network within the axon and discussed how the axonal cytoskeleton contributes to the function of these various structures and processes. Identifying the organization of both the microtubule and actin cytoskeleton within the axon shaft, AIS and presynaptic sites has increased our understanding of their contribution to axon functioning. However, comprehensive knowledge on the how the cytoskeleton organization relates to the function of specific axonal structures is limited. Therefore, it will be important to elucidate the currently ambiguous role of actin within the presynapse to understand the molecular mechanisms of presynaptic organization and functioning. Also, it will be important to examine the contribution of MTs in presynaptic functioning. In addition, unraveling the molecular mechanisms of the barrier function of the AIS and how the underlying cytoskeleton contributes to this function will increase 
our understanding of the mechanisms of polarized transport. Moreover, further identification of motor proteins, their adaptors, cargoes, and regulatory mechanisms will be essential to understand the precise molecular mechanisms underlying axonal transport. Since an increasing numbers of neurodevelopmental and neurodegenerative diseases are being linked to defects in the axonal transport machinery, fundamental knowledge about intracellular transport mechanisms and cytoskeleton organization will be important for the development of new therapeutic strategies.

\section{References}

Akhmanova, A., and Hammer, J. A. III (2010). Linking molecular motors to membrane cargo. Curr. Opin. Cell Biol. 22, 479-487. doi: 10.1016/j.ceb.2010. 04.008

Akhmanova, A., and Steinmetz, M. O. (2010). Microtubule +TIPs at a glance. J. Cell Sci. 123, 3415-3419. doi: 10.1242/jcs.062414

Al-Bassam, S., Xu, M., Wandless, T. J., and Arnold, D. B. (2012). Differential trafficking of transport vesicles contributes to the localization of dendritic proteins. Cell Rep. 2, 89-100. doi: 10.1016/j.celrep.2012.05.018

Baas, P. W., Deitch, J. S., Black, M. M., and Banker, G. A. (1988). Polarity orientation of microtubules in hippocampal neurons: uniformity in the axon and nonuniformity in the dendrite. Proc. Natl. Acad. Sci. U S A 85, 8335-8339. doi: 10.1073/pnas.85.21.8335

Babic, M., Russo, G. J., Wellington, A. J., Sangston, R. M., Gonzalez, M., and Zinsmaier, K. E. (2015). Miro's N-terminal GTPase domain is required for transport of mitochondria into axons and dendrites. J. Neurosci. 35, 5754-5771. doi: 10.1523/JNEUROSCI.1035-14.2015

Barnes, A. P., and Polleux, F. (2009). Establishment of axon-dendrite polarity in developing neurons. Annu. Rev. Neurosci. 32, 347-381. doi: 10.1146/annurev. neuro.31.060407.125536

Bennett, V., and Lorenzo, D. N. (2013). Spectrin- and ankyrin-based membrane domains and the evolution of vertebrates. Curr. Top. Membr. 72, 1-37. doi: 10. 1016/b978-0-12-417027-8.00001-5

Bernstein, B. W. M., Maloney, M. T., and Bamburg, J. R. (2011). "Actin and diseases of the nervous system," in Neurobiology of Actin, eds G. L. Gianluca and M. L. Lorene (New York, NY: Springer), 201-234.

Boiko, T., Vakulenko, M., Ewers, H., Yap, C. C., Norden, C., and Winckler, B. (2007). Ankyrin-dependent and -independent mechanisms orchestrate axonal compartmentalization of L1 family members neurofascin and L1/neuron-glia cell adhesion molecule. J. Neurosci. 27, 590-603. doi: 10.1523/jneurosci.430206.2007

Bressloff, P. C., and Levien, E. (2015). Synaptic democracy and vesicular transport in axons. Phys. Rev. Lett. 114:168101. doi: 10.1103/physrevlett.114.168101

Breuss, M., and Keays, D. A. (2014). Microtubules and neurodevelopmental disease: the movers and the makers. Adv. Exp. Med. Biol. 800, 75-96. doi: 10. 1007/978-94-007-7687-6_5

Brickley, K., and Stephenson, F. A. (2011). Trafficking kinesin protein (TRAK)mediated transport of mitochondria in axons of hippocampal neurons. J. Biol. Chem. 286, 18079-18092. doi: 10.1074/jbc.M111.236018

Bury, L. A., and Sabo, S. L. (2011). Coordinated trafficking of synaptic vesicle and active zone proteins prior to synapse formation. Neural Dev. 6:24. doi: 10 . 1186/1749-8104-6-24

Bury, L. A., and Sabo, S. L. (2014). Dynamic mechanisms of neuroligin-dependent presynaptic terminal assembly in living cortical neurons. Neural Dev. 9:13. doi: 10.1186/1749-8104-9-13

Cai, Q., Gerwin, C., and Sheng, Z. H. (2005). Syntabulin-mediated anterograde transport of mitochondria along neuronal processes. J. Cell Biol. 170, 959-969. doi: $10.1083 /$ jcb. 200506042

Cai, Q., Pan, P. Y., and Sheng, Z. H. (2007). Syntabulin-kinesin-1 family member 5B-mediated axonal transport contributes to activity-dependent presynaptic assembly. J. Neurosci. 27, 7284-7296. doi: 10.1523/jneurosci.073107.2007

\section{Acknowledgments}

We would like to thank Dieudonnée van de Willige for very helpful comments on the manuscript. This work was supported by the Netherlands Organization for Scientific Research (NWOALW-VICI, CCH), the Foundation for Fundamental Research on Matter ((FOM) CCH), which is part of the NWO, the Netherlands Organization for Health Research and Development (ZonMW-TOP, CCH), the European Research Council (ERC) (ERC-consolidator, $\mathrm{CCH}$ ).

Campbell, P. D., Shen, K., Sapio, M. R., Glenn, T. D., Talbot, W. S., and Marlow, F. L. (2014). Unique function of kinesin Kif5A in localization of mitochondria in axons. J. Neurosci. 34, 14717-14732. doi: 10.1523/JNEUROSCI.277014.2014

Cheng, L., Desai, J., Miranda, C. J., Duncan, J. S., Qiu, W., Nugent, A. A., et al. (2014). Human CFEOM1 mutations attenuate KIF21A autoinhibition and cause oculomotor axon stalling. Neuron 82, 334-349. doi: 10.1016/j.neuron. 2014.02.038

Chia, P. H., Chen, B., Li, P., Rosen, M. K., and Shen, K. (2014). Local F-actin network links synapse formation and axon branching. Cell 156, 208-220. doi: 10.1016/j.cell.2013.12.009

Chia, P. H., Li, P., and Shen, K. (2013). Cell biology in neuroscience: cellular and molecular mechanisms underlying presynapse formation. J. Cell Biol. 203, 11-22. doi: 10.1083/jcb.201307020

Chia, P. H., Patel, M. R., and Shen, K. (2012). NAB-1 instructs synapse assembly by linking adhesion molecules and F-actin to active zone proteins. Nat. Neurosci. 15, 234-242. doi: 10.1038/nn.2991

Chua, J. J. (2014). Macromolecular complexes at active zones: integrated nanomachineries for neurotransmitter release. Cell. Mol. Life Sci. 71, 3903-3916. doi: 10.1007/s00018-014-1657-5

Chua, J. J., Kindler, S., Boyken, J., and Jahn, R. (2010). The architecture of an excitatory synapse. J. Cell Sci. 123, 819-823. doi: 10.1242/jcs.052696

Cingolani, L. A., and Goda, Y. (2008). Actin in action: the interplay between the actin cytoskeleton and synaptic efficacy. Nat. Rev. Neurosci. 9, 344-356. doi: 10. $1038 /$ nrn2373

Cleveland, D. W., Hwo, S. Y., and Kirschner, M. W. (1977). Purification of tau, a microtubule-associated protein that induces assembly of microtubules from purified tubulin. J. Mol. Biol. 116, 207-225. doi: 10.1016/0022-2836(77) 90213-3

Colin, E., Zala, D., Liot, G., Rangone, H., Borrell-Pagès, M., Li, X. J., et al. (2008). Huntingtin phosphorylation acts as a molecular switch for anterograde/retrograde transport in neurons. EMBO J. 27, 2124-2134. doi: 10. 1038/emboj.2008.133

Conway, L., Gramlich, M. W., Ali Tabei, S. M., and Ross, J. L. (2014). Microtubule orientation and spacing within bundles is critical for long-range kinesin-1 motility. Cytoskeleton (Hoboken) 71, 595-610. doi: 10.1002/cm.21197

De Vos, K. J., Grierson, A. J., Ackerley, S., and Miller, C. C. (2008). Role of axonal transport in neurodegenerative diseases. Annu. Rev. Neurosci. 31, 151-173. doi: 10.1146/annurev.neuro.31.061307.090711

Dehmelt, L., and Halpain, S. (2005). The MAP2/Tau family of microtubuleassociated proteins. Genome Biol. 6:204. doi: 10.1186/gb-2004-6-1-204

del Castillo, U., Lu, W., Winding, M., Lakonishok, M., and Gelfand, V. I. (2015). Pavarotti/MKLP1 regulates microtubule sliding and neurite outgrowth in drosophila neurons. Curr. Biol. 25, 200-205. doi: 10.1016/j.cub.2014.11.008

Dent, E. W., and Kalil, K. (2001). Axon branching requires interactions between dynamic microtubules and actin filaments. J. Neurosci. 21, 9757-9769.

Derisbourg, M., Leghay, C., Chiappetta, G., Fernandez-Gomez, F. J., Laurent, C., Demeyer, D., et al. (2015). Role of the Tau N-terminal region in microtubule stabilization revealed by new endogenous truncated forms. Sci. Rep. 5:9659. doi: 10.1038/srep09659

D’Este, E., Kamin, D., Göttfert, F., El-Hady, A., and Hell, S. W. (2015). STED nanoscopy reveals the ubiquity of subcortical cytoskeleton periodicity in living neurons. Cell Rep. 10, 1246-1251. doi: 10.1016/j.celrep.2015.02.007 
Diefenbach, R. J., Diefenbach, E., Douglas, M. W., and Cunningham, A. L. (2002). The heavy chain of conventional kinesin interacts with the SNARE proteins SNAP25 and SNAP23. Biochemistry 41, 14906-14915. doi: 10.1021/bi026417u

Dillon, C., and Goda, Y. (2005). The actin cytoskeleton: integrating form and function at the synapse. Annu. Rev. Neurosci. 28, 25-55. doi: 10.1146/annurev. neuro.28.061604.135757

Dixit, R., Ross, J. L., Goldman, Y. E., and Holzbaur, E. L. (2008). Differential regulation of dynein and kinesin motor proteins by tau. Science 319, 1086-1089. doi: 10.1126/science.1152993

Dotti, C. G., Sullivan, C. A., and Banker, G. A. (1988). The establishment of polarity by hippocampal neurons in culture. J. Neurosci. 8, 1454-1468.

Drechsel, D. N., Hyman, A. A., Cobb, M. H., and Kirschner, M. W. (1992). Modulation of the dynamic instability of tubulin assembly by the microtubuleassociated protein tau. Mol. Biol. Cell 3, 1141-1154. doi: 10.1091/mbc. 3.10 .1141

Drummond, D. R. (2011). Regulation of microtubule dynamics by kinesins. Semin. Cell Dev. Biol. 22, 927-934. doi: 10.1016/j.semcdb.2011.09.021

Encalada, S. E., and Goldstein, L. S. (2014). Biophysical challenges to axonal transport: motor-cargo deficiencies and neurodegeneration. Annu. Rev. Biophys. 43, 141-169. doi: 10.1146/annurev-biophys-051013-022746

Eva, R., and Fawcett, J. (2014). Integrin signalling and traffic during axon growth and regeneration. Curr. Opin. Neurobiol. 27, 179-185. doi: 10.1016/j.conb.2014. 03.018

Farkhondeh, A., Niwa, S., Takei, Y., and Hirokawa, N. (2015). Characterizing KIF16B in neurons reveals a novel intramolecular "stalk inhibition" mechanism that regulates its capacity to potentiate the selective somatodendritic localization of early endosomes. J. Neurosci. 35, 5067-5086. doi: 10.1523/JNEUROSCI.4240-14.2015

Flynn, K. C., Hellal, F., Neukirchen, D., Jacob, S., Tahirovic, S., Dupraz, S., et al. (2012). ADF/cofilin-mediated actin retrograde flow directs neurite formation in the developing brain. Neuron 76, 1091-1107. doi: 10.1016/j.neuron.2012. 09.038

Flynn, K. C., Pak, C. W., Shaw, A. E., Bradke, F., and Bamburg, J. R. (2009). Growth cone-like waves transport actin and promote axonogenesis and neurite branching. Dev. Neurobiol. 69, 761-779. doi: 10.1002/dneu.20734

Franker, M. A., and Hoogenraad, C. C. (2013). Microtubule-based transport - basic mechanisms, traffic rules and role in neurological pathogenesis. J. Cell Sci. 126, 2319-2329. doi: 10.1242/jcs.115030

Franssen, E. H., Zhao, R. R., Koseki, H., Kanamarlapudi, V., Hoogenraad, C. C., Eva, R., et al. (2015). Exclusion of integrins from CNS axons is regulated by arf6 activation and the AIS. J. Neurosci. 35, 8359-8375. doi: 10.1523/JNEUROSCI. 2850-14.2015

Fransson, S., Ruusala, A., and Aspenström, P. (2006). The atypical Rho GTPases Miro-1 and Miro-2 have essential roles in mitochondrial trafficking. Biochem. Biophys. Res. Commun. 344, 500-510. doi: 10.1016/j.bbrc.2006.03.163

Fu, M. M., and Holzbaur, E. L. (2013). JIP1 regulates the directionality of APP axonal transport by coordinating kinesin and dynein motors. J. Cell Biol. 202, 495-508. doi: $10.1083 /$ jcb. 201302078

Fujita, T., Maturana, A. D., Ikuta, J., Hamada, J., Walchli, S., Suzuki, T., et al. (2007). Axonal guidance protein FEZ1 associates with tubulin and kinesin motor protein to transport mitochondria in neurites of NGF-stimulated PC12 cells. Biochem. Biophys. Res. Commun. 361, 605-610. doi: 10.1016/j.bbrc.2007. 07.050

Gallo, G. (2011). The cytoskeletal and signaling mechanisms of axon collateral branching. Dev. Neurobiol. 71, 201-220. doi: 10.1002/dneu.20852

Gandini, M. A., Henríquez, D. R., Grimaldo, L., Sandoval, A., Altier, C., Zamponi, G. W., et al. (2014). CaV2.2 channel cell surface expression is regulated by the light chain 1 (LC1) of the microtubule-associated protein B (MAP1B) via UBE2L3-mediated ubiquitination and degradation. Pflugers. Arch. 466, 2113-2126. doi: 10.1007/s00424-014-1476-4

Ganguly, A., Tang, Y., Wang, L., Ladt, K., Loi, J., Dargent, B., et al. (2015). A dynamic formin-dependent deep F-actin network in axons. J. Cell Biol. doi: 10. 1083/jcb.201506110 [Epub ahead of print].

Gentil, B. J., and Cooper, L. (2012). Molecular basis of axonal dysfunction and traffic impairments in CMT. Brain Res. Bull. 88, 444-453. doi: 10.1016/j. brainresbull.2012.05.003

Goldstein, A. Y., Wang, X., and Schwarz, T. L. (2008). Axonal transport and the delivery of pre-synaptic components. Curr. Opin. Neurobiol. 18, 495-503. doi: 10.1016/j.conb.2008.10.003
Gomez, T. M., and Letourneau, P. C. (2014). Actin dynamics in growth cone motility and navigation. J. Neurochem. 129, 221-234. doi: 10.1111/jnc.12506

Gordon-Weeks, P. R., and Fournier, A. E. (2014). Neuronal cytoskeleton in synaptic plasticity and regeneration. J. Neurochem. 129, 206-212. doi: 10. $1111 /$ inc. 12502

Grubb, M. S., and Burrone, J. (2010). Building and maintaining the axon initial segment. Curr. Opin. Neurobiol. 20, 481-488. doi: 10.1016/j.conb.2010.04.012

Gundelfinger, E. D., and Fejtova, A. (2012). Molecular organization and plasticity of the cytomatrix at the active zone. Curr. Opin. Neurobiol. 22, 423-430. doi: 10. 1016/j.conb.2011.10.005

Hall, D. H., and Hedgecock, E. M. (1991). Kinesin-related gene unc-104 is required for axonal transport of synaptic vesicles in C. elegans. Cell 65, 837-847. doi: 10. 1016/0092-8674(91)90391-b

Halpain, S. (2003). Actin in a supporting role. Nat. Neurosci. 6, 101-102. doi: 10. 1038/nn0203-101

Hammond, J. W., Blasius, T. L., Soppina, V., Cai, D., and Verhey, K. J. (2010). Autoinhibition of the kinesin-2 motor KIF17 via dual intramolecular mechanisms. J. Cell Biol. 189, 1013-1025. doi: 10.1083/jcb.201001057

Hammond, J. W., Cai, D., Blasius, T. L., Li, Z., Jiang, Y., Jih, G. T., et al. (2009). Mammalian kinesin-3 motors are dimeric in vivo and move by processive motility upon release of autoinhibition. PLoS Biol. 7:e72. doi: 10.1371/journal. pbio. 1000072

Hedstrom, K. L., Xu, X., Ogawa, Y., Frischknecht, R., Seidenbecher, C. I., Shrager, P., et al. (2007). Neurofascin assembles a specialized extracellular matrix at the axon initial segment. J. Cell Biol. 178, 875-886. doi: 10.1083/jcb. 200705119

Hellal, F., Hurtado, A., Ruschel, J., Flynn, K. C., Laskowski, C. J., Umlauf, M., et al. (2011). Microtubule stabilization reduces scarring and causes axon regeneration after spinal cord injury. Science 331, 928-931. doi: 10. $1126 /$ science. 1201148

Hirokawa, N. (1982). Cross-linker system between neurofilaments, microtubules, and membranous organelles in frog axons revealed by the quick-freeze, deepetching method. J. Cell Biol. 94, 129-142. doi: 10.1083/jcb.94.1.129

Hirokawa, N., Niwa, S., and Tanaka, Y. (2010). Molecular motors in neurons: transport mechanisms and roles in brain function, development and disease. Neuron 68, 610-638. doi: 10.1016/j.neuron.2010.09.039

Hirokawa, N., and Takemura, R. (2005). Molecular motors and mechanisms of directional transport in neurons. Nat. Rev. Neurosci. 6, 201-214. doi: 10. $1038 /$ nrn 1624

Janke, C., and Bulinski, J. C. (2011). Post-translational regulation of the microtubule cytoskeleton: mechanisms and functions. Nat. Rev. Mol. Cell Biol. 12, 773-786. doi: $10.1038 / \mathrm{nrm} 3227$

Janke, C., and Kneussel, M. (2010). Tubulin post-translational modifications: encoding functions on the neuronal microtubule cytoskeleton. Trends Neurosci. 33, 362-372. doi: 10.1016/j.tins.2010.05.001

Jones, S. L., Korobova, F., and Svitkina, T. (2014). Axon initial segment cytoskeleton comprises a multiprotein submembranous coat containing sparse actin filaments. J. Cell Biol. 205, 67-81. doi: 10.1083/jcb.201401045

Kaan, H. Y., Hackney, D. D., and Kozielski, F. (2011). The structure of the kinesin1 motor-tail complex reveals the mechanism of autoinhibition. Science 333, 883-885. doi: 10.1126/science.1204824

Kalil, K., and Dent, E. W. (2014). Branch management: mechanisms of axon branching in the developing vertebrate CNS. Nat. Rev. Neurosci. 15, 7-18. doi: $10.1038 / \mathrm{nrn} 3650$

Kamal, A., Stokin, G. B., Yang, Z., Xia, C. H., and Goldstein, L. S. (2000). Axonal transport of amyloid precursor protein is mediated by direct binding to the kinesin light chain subunit of kinesin-I. Neuron 28, 449-459. doi: 10. 1016/s0896-6273(00)00124-0

Kapitein, L. C., and Hoogenraad, C. C. (2011). Which way to go? cytoskeletal organization and polarized transport in neurons. Mol. Cell. Neurosci. 46, 9-20. doi: 10.1016/j.mcn.2010.08.015

Kapitein, L. C., Schlager, M. A., Kuijpers, M., Wulf, P. S., van Spronsen, M., MacKintosh, F. C., et al. (2010). Mixed microtubules steer dynein-driven cargo transport into dendrites. Curr. Biol. 20, 290-299. doi: 10.1016/j.cub.2009. 12.052

Katsuno, H., Toriyama, M., Hosokawa, Y., Mizuno, K., Ikeda, K., Sakumura, Y., et al. (2015). Actin migration driven by directional assembly and disassembly of membrane-anchored actin filaments. Cell Rep. 12, 648-660. doi: 10.1016/j. celrep.2015.06.048 
Ketschek, A., Jones, S., Spillane, M., Korobova, F., Svitkina, T., and Gallo, G. (2015). Nerve growth factor promotes reorganization of the axonal microtubule array at sites of axon collateral branching. Dev. Neurobiol. doi: 10.1002/dneu. 22294 [Epub ahead of print].

Klemmer, P., Meredith, R. M., Holmgren, C. D., Klychnikov, O. I., Stahl-Zeng, J., Loos, M., et al. (2011). Proteomics, ultrastructure and physiology of hippocampal synapses in a fragile $\mathrm{X}$ syndrome mouse model reveal presynaptic phenotype. J. Biol. Chem. 286, 25495-25504. doi: 10.1074/jbc.m110. 210260

Koch, N., Kobler, O., Thomas, U., Qualmann, B., and Kessels, M. M. (2014). Terminal axonal arborization and synaptic bouton formation critically rely on abp1 and the arp2/3 complex. PLoS One 9:e97692. doi: 10.1371/journal.pone. 0097692

Kolodkin, A. L., and Tessier-Lavigne, M. (2011). Mechanisms and molecules of neuronal wiring: a primer. Cold Spring Harb. Perspect. Biol. 3:a001727. doi: 10. 1101/cshperspect.a001727

Kondo, M., Takei, Y., and Hirokawa, N. (2012). Motor protein KIF1A is essential for hippocampal synaptogenesis and learning enhancement in an enriched environment. Neuron 73, 743-757. doi: 10.1016/j.neuron.2011.12.020

Korobova, F., and Svitkina, T. (2010). Molecular architecture of synaptic actin cytoskeleton in hippocampal neurons reveals a mechanism of dendritic spine morphogenesis. Mol. Biol. Cell 21, 165-176. doi: 10.1091/mbc.E09-07-0596

Kurup, N., Yan, D., Goncharov, A., and Jin, Y. (2015). Dynamic microtubules drive circuit rewiring in the absence of neurite remodeling. Curr. Biol. 25, 1594-1605. doi: 10.1016/j.cub.2015.04.061

Lai, H. C., and Jan, L. Y. (2006). The distribution and targeting of neuronal voltagegated ion channels. Nat. Rev. Neurosci. 7, 548-562. doi: 10.1038/nrn1938

Lee, J. R., Shin, H., Choi, J., Ko, J., Kim, S., Lee, H. W., et al. (2004). An intramolecular interaction between the FHA domain and a coiled coil negatively regulates the kinesin motor KIF1A. EMBO J. 23, 1506-1515. doi: 10. 1038/sj.emboj.7600164

Leenders, A. G., Lin, L., Huang, L. D., Gerwin, C., Lu, P. H., and Sheng, Z. H. (2008). The role of MAP1A light chain 2 in synaptic surface retention of Cav2.2 channels in hippocampal neurons. J. Neurosci. 28, 11333-11346. doi: 10. 1523/JNEUROSCI.3078-08.2008

Lepicard, S., Franco, B., de Bock, F., and Parmentier, M. L. (2014). A presynaptic role of microtubule-associated protein 1/Futsch in drosophila: regulation of active zone number and neurotransmitter release. J. Neurosci. 34, 6759-6771. doi: 10.1523/JNEUROSCI.4282-13.2014

Leterrier, C., and Dargent, B. (2014). No pasaran! role of the axon initial segment in the regulation of protein transport and the maintenance of axonal identity. Semin. Cell Dev. Biol. 27, 44-51. doi: 10.1016/j.semcdb.2013.11.001

Leterrier, C., Vacher, H., Fache, M. P., d'Ortoli, S. A., Castets, F., Autillo-Touati, A., et al. (2011). End-binding proteins EB3 and EB1 link microtubules to ankyrin-G in the axon initial segment. Proc. Natl. Acad. Sci. U S A 108, 8826-8831. doi: 10.1073/pnas.1018671108

Letourneau, P. C. (2009). Actin in axons: stable scaffolds and dynamic filaments. Results Probl. Cell Differ. 48, 65-90. doi: 10.1007/400_2009_15

Liu, G., and Dwyer, T. (2014). Microtubule dynamics in axon guidance. Neurosci. Bull. 30, 569-583. doi: 10.1007/s12264-014-1444-6

Liu, Y. T., Laurá, M., Hersheson, J., Horga, A., Jaunmuktane, Z., Brandner, S., et al. (2014). Extended phenotypic spectrum of KIF5A mutations: from spastic paraplegia to axonal neuropathy. Neurology 83, 612-619. doi: 10.1212/WNL. 0000000000000691

Liu, Y. F., Sowell, S. M., Luo, Y., Chaubey, A., Cameron, R. S., Kim, H. G., et al. (2015). Autism and intellectual disability-associated KIRREL3 interacts with neuronal proteins MAP1B and MYO16 with potential roles in neurodevelopment. PLoS One 10:e0123106. doi: 10.1371/journal.pone. 0123106

Lo, K. Y., Kuzmin, A., Unger, S. M., Petersen, J. D., and Silverman, M. A. (2011). KIF1A is the primary anterograde motor protein required for the axonal transport of dense-core vesicles in cultured hippocampal neurons. Neurosci. Lett. 491, 168-173. doi: 10.1016/j.neulet.2011.01.018

Lu, W., Fox, P., Lakonishok, M., Davidson, M. W., and Gelfand, V. I. (2013). Initial neurite outgrowth in drosophila neurons is driven by kinesin-powered microtubule sliding. Curr. Biol. 23, 1018-1023. doi: 10.1016/j.cub.2013.04.050

Lu, W., Lakonishok, M., and Gelfand, V. I. (2015). Kinesin-1-powered microtubule sliding initiates axonal regeneration in drosophila cultured neurons. Mol. Biol. Cell 26, 1296-1307. doi: 10.1091/mbc.E14-10-1423
Lucido, A. L., Suarez Sanchez, F., Thostrup, P., Kwiatkowski, A. V., Leal-Ortiz, S., Gopalakrishnan, G., et al. (2009). Rapid assembly of functional presynaptic boutons triggered by adhesive contacts. J. Neurosci. 29, 12449-12466. doi: 10. 1523/JNEUROSCI.1381-09.2009

Lukinavičius, G., Reymond, L., D’Este, E., Masharina, A., Göttfert, F., Ta, H., et al. (2014). Fluorogenic probes for live-cell imaging of the cytoskeleton. Nat. Methods 11, 731-733. doi: 10.1038/nmeth.2972

Luo, L. (2002). Actin cytoskeleton regulation in neuronal morphogenesis and structural plasticity. Annu. Rev. Cell Dev. Biol. 18, 601-635. doi: 10. 1146/annurev.cellbio.18.031802.150501

Maas, C., Torres, V. I., Altrock, W. D., Leal-Ortiz, S., Wagh, D., Terry-Lorenzo, R. T., et al. (2012). Formation of golgi-derived active zone precursor vesicles. J. Neurosci. 32, 11095-11108. doi: 10.1523/JNEUROSCI.0195-12.2012

Maday, S., Twelvetrees, A. E., Moughamian, A. J., and Holzbaur, E. L. (2014). Axonal transport: cargo-specific mechanisms of motility and regulation. Neuron 84, 292-309. doi: 10.1016/j.neuron.2014.10.019

Maeder, C. I., Shen, K., and Hoogenraad, C. C. (2014). Axon and dendritic trafficking. Curr. Opin. Neurobiol. 27, 165-170. doi: 10.1016/j.conb.2014. 03.015

Meyer, M. P., and Smith, S. J. (2006). Evidence from in vivo imaging that synaptogenesis guides the growth and branching of axonal arbors by two distinct mechanisms. J. Neurosci. 26, 3604-3614. doi: 10.1523/jneurosci.022306.2006

Millecamps, S., and Julien, J. P. (2013). Axonal transport deficits and neurodegenerative diseases. Nat. Rev. Neurosci. 14, 161-176. doi: 10. $1038 / \mathrm{nrn} 3380$

Miller, K. E., DeProto, J., Kaufmann, N., Patel, B. N., Duckworth, A., and Van Vactor, D. (2005). Direct observation demonstrates that liprin-alpha is required for trafficking of synaptic vesicles. Curr. Biol. 15, 684-689. doi: 10.1016/j.cub. 2005.02.061

Mitchison, T., and Kirschner, M. (1984). Dynamic instability of microtubule growth. Nature 312, 237-242. doi: 10.1038/312237a0

Morikawa, M., Yajima, H., Nitta, R., Inoue, S., Ogura, T., Sato, C., et al. (2015). $\mathrm{X}$-ray and Cryo-EM structures reveal mutual conformational changes of kinesin and GTP-state microtubules upon binding. EMBO J. 34, 1270-1286. doi: 10.15252/embj.201490588

Morton, A. M., Cunningham, A. L., and Diefenbach, R. J. (2010). Kinesin-1 plays a role in transport of SNAP-25 to the plasma membrane. Biochem. Biophys. Res. Commun. 391, 388-393. doi: 10.1016/j.bbrc.2009.11.068

Nahm, M., Lee, M. J., Parkinson, W., Lee, M., Kim, H., Kim, Y. J., et al. (2013). Spartin regulates synaptic growth and neuronal survival by inhibiting BMPmediated microtubule stabilization. Neuron 77, 680-695. doi: 10.1016/j.neuron. 2012.12.015

Nakada, C., Ritchie, K., Oba, Y., Nakamura, M., Hotta, Y., Iino, R., et al. (2003). Accumulation of anchored proteins forms membrane diffusion barriers during neuronal polarization. Nat. Cell. Biol. 5, 626-632. doi: 10.1038/ncb1009

Nakata, T., Niwa, S., Okada, Y., Perez, F., and Hirokawa, N. (2011). Preferential binding of a kinesin-1 motor to GTP-tubulin-rich microtubules underlies polarized vesicle transport. J. Cell Biol. 194, 245-255. doi: 10.1083/jcb. 201104034

Nangaku, M., Sato-Yoshitake, R., Okada, Y., Noda, Y., Takemura, R., Yamazaki, H., et al. (1994). KIF1B, a novel microtubule plus end-directed monomeric motor protein for transport of mitochondria. Cell 79, 1209-1220. doi: 10. 1016/0092-8674(94)90012-4

Nelson, J. C., Stavoe, A. K., and Colón-Ramos, D. A. (2013). The actin cytoskeleton in presynaptic assembly. Cell. Adh. Migr. 7, 379-387. doi: 10.4161/cam.24803

Niwa, S. (2015). Kinesin superfamily proteins and the regulation of microtubule dynamics in morphogenesis. Anat. Sci. Int. 90, 1-6. doi: 10.1007/s12565-0140259-5

Niwa, S., Takahashi, H., and Hirokawa, N. (2013). $\beta$-Tubulin mutations that cause severe neuropathies disrupt axonal transport. EMBO J. 32, 1352-1364. doi: 10. 1038/emboj.2013.59

Niwa, S., Tanaka, Y., and Hirokawa, N. (2008). KIF1Bbeta- and KIF1A-mediated axonal transport of presynaptic regulator Rab3 occurs in a GTP-dependent manner through DENN/MADD. Nat. Cell. Biol. 10, 1269-1279. doi: 10. $1038 /$ ncb 1785

Ogawa, Y., and Rasband, M. N. (2008). The functional organization and assembly of the axon initial segment. Curr. Opin. Neurobiol. 18, 307-313. doi: 10.1016/j. conb.2008.08.008 
Okada, Y., Yamazaki, H., Sekine-Aizawa, Y., and Hirokawa, N. (1995). The neuron-specific kinesin superfamily protein KIF1A is a unique monomeric motor for anterograde axonal transport of synaptic vesicle precursors. Cell 81, 769-780. doi: 10.1016/0092-8674(95)90538-3

Özkan, E., Chia, P. H., Wang, R. R., Goriatcheva, N., Borek, D., Otwinowski, Z., et al. (2014). Extracellular architecture of the SYG-1/SYG-2 adhesion complex instructs synaptogenesis. Cell 156, 482-494. doi: 10.1016/j.cell. 2014.01.004

Patil, H., Cho, K. I., Lee, J., Yang, Y., Orry, A., and Ferreira, P. A. (2013). Kinesin-1 and mitochondrial motility control by discrimination of structurally equivalent but distinct subdomains in Ran-GTP-binding domains of Ran-binding protein 2. Open Biol. 3:120183. doi: 10.1098/rsob.120183

Petersen, J. D., Kaech, S., and Banker, G. (2014). Selective microtubule-based transport of dendritic membrane proteins arises in concert with axon specification. J. Neurosci. 34, 4135-4147. doi: 10.1523/jneurosci.3779-13.2014

Pilling, A. D., Horiuchi, D., Lively, C. M., and Saxton, W. M. (2006). Kinesin-1 and dynein are the primary motors for fast transport of mitochondria in drosophila motor axons. Mol. Biol. Cell 17, 2057-2068. doi: 10.1091/mbc.e05-06-0526

Rasband, M. N. (2010). The axon initial segment and the maintenance of neuronal polarity. Nat. Rev. Neurosci. 11, 552-562. doi: 10.1038/nrn2852

Robberecht, W., and Philips, T. (2013). The changing scene of amyotrophic lateral sclerosis. Nat. Rev. Neurosci. 14, 248-264. doi: 10.1038/nrn3430

Ruschel, J., Hellal, F., Flynn, K. C., Dupraz, S., Elliott, D. A., Tedeschi, A., et al. (2015). Axonal regeneration. Systemic administration of epothilone B promotes axon regeneration after spinal cord injury. Science 348, 347-352. doi: 10.1126/science.aaa2958

Rust, M. B., and Maritzen, T. (2015). Relevance of presynaptic actin dynamics for synapse function and mouse behavior. Exp. Cell. Res. 335, 165-171. doi: 10. 1016/j.yexcr.2014.12.020

Sainath, R., and Gallo, G. (2015). Cytoskeletal and signaling mechanisms of neurite formation. Cell Tissue Res. 359, 267-278. doi: 10.1007/s00441-014-1955-0

Sankaranarayanan, S., Atluri, P. P., and Ryan, T. A. (2003). Actin has a molecular scaffolding, not propulsive, role in presynaptic function. Nat. Neurosci. 6, 127-135. doi: 10.1038/nn1002

Schlager, M. A., and Hoogenraad, C. C. (2009). Basic mechanisms for recognition and transport of synaptic cargos. Mol. Brain 2:25. doi: 10.1186/17566606-2-25

Schuyler, S. C., and Pellman, D. (2001). Microtubule "plus-end-tracking proteins": the end is just the beginning. Cell 105, 421-424. doi: 10.1002/9780470015902. a0025979

Shapira, M., Zhai, R. G., Dresbach, T., Bresler, T., Torres, V. I., Gundelfinger, E. D., et al. (2003). Unitary assembly of presynaptic active zones from piccolo-bassoon transport vesicles. Neuron 38, 237-252. doi: 10.1016/s08966273(03)00207-1

Shin, H., Wyszynski, M., Huh, K. H., Valtschanoff, J. G., Lee, J. R., Ko, J., et al. (2003). Association of the kinesin motor KIF1A with the multimodular protein liprin-alpha. J. Biol. Chem. 278, 11393-11401. doi: 10.1074/jbc.m211874200

Song, Y., and Brady, S. T. (2015). Post-translational modifications of tubulin: pathways to functional diversity of microtubules. Trends Cell Biol. 25, 125-136. doi: $10.1016 /$ j.tcb.2014.10.004

Song, A. H., Wang, D., Chen, G., Li, Y., Luo, J., Duan, S., et al. (2009). A selective filter for cytoplasmic transport at the axon initial segment. Cell 136, 1148-1160. doi: 10.1016/j.cell.2009.01.016

Sousa, V. L., Bellani, S., Giannandrea, M., Yousuf, M., Valtorta, F., Meldolesi, J., et al. (2009). alpha-synuclein and its A30P mutant affect actin cytoskeletal structure and dynamics. Mol. Biol. Cell 20, 3725-3739. doi: 10.1091/mbc.e0803-0302

Spillane, M., Ketschek, A., Jones, S. L., Korobova, F., Marsick, B., Lanier, L., et al. (2011). The actin nucleating Arp2/3 complex contributes to the formation of axonal filopodia and branches through the regulation of actin patch precursors to filopodia. Dev. Neurobiol. 71, 747-758. doi: 10.1002/dneu.20907

Stepanova, T., Slemmer, J., Hoogenraad, C. C., Lansbergen, G., Dortland, B., De Zeeuw, C. I., et al. (2003). Visualization of microtubule growth in cultured neurons via the use of EB3-GFP (end-binding protein 3-green fluorescent protein). J. Neurosci. 23, 2655-2664.

Stephan, R., Goellner, B., Moreno, E., Frank, C. A., Hugenschmidt, T., Genoud, C., et al. (2015). Hierarchical microtubule organization controls axon caliber and transport and determines synaptic structure and stability. Dev. Cell 33, 5-21. doi: 10.1016/j.devcel.2015.02.003
Stiess, M., and Bradke, F. (2011). Neuronal polarization: the cytoskeleton leads the way. Dev. Neurobiol. 71, 430-444. doi: 10.1002/dneu.20849

Stone, M. C., Roegiers, F., and Rolls, M. M. (2008). Microtubules have opposite orientation in axons and dendrites of drosophila neurons. Mol. Biol. Cell 19, 4122-4129. doi: 10.1091/mbc.e07-10-1079

Su, Q., Cai, Q., Gerwin, C., Smith, C. L., and Sheng, Z. H. (2004). Syntabulin is a microtubule-associated protein implicated in syntaxin transport in neurons. Nat. cell Biol. 6, 941-953. doi: 10.1038/ncb1169

Sudhof, T. C. (2004). The synaptic vesicle cycle. Annu. Rev. Neurosci. 27, 509-547. doi: 10.1146/annurev.neuro.26.041002.131412

Südhof, T. C. (2012). The presynaptic active zone. Neuron 75, 11-25. doi: 10. 1016/j.neuron.2012.06.012

Sugie, A., Hakeda-Suzuki, S., Suzuki, E., Silies, M., Shimozono, M., Mohl, C., et al. (2015). Molecular remodeling of the presynaptic active zone of drosophila photoreceptors via activity-dependent feedback. Neuron 86, 711-725. doi: 10. 1016/j.neuron.2015.03.046

Sun, T., Qiao, H., Pan, P. Y., Chen, Y., and Sheng, Z. H. (2013). Motile axonal mitochondria contribute to the variability of presynaptic strength. Cell Rep. 4, 413-419. doi: 10.1016/j.celrep.2013.06.040

Tanaka, Y., Kanai, Y., Okada, Y., Nonaka, S., Takeda, S., Harada, A., et al. (1998). Targeted disruption of mouse conventional kinesin heavy chain, kif5B, results in abnormal perinuclear clustering of mitochondria. Cell 93, 1147-1158. doi: 10.1016/s0092-8674(00)81459-2

Tanaka, K., Sugiura, Y., Ichishita, R., Mihara, K., and Oka, T. (2011). KLP6: a newly identified kinesin that regulates the morphology and transport of mitochondria in neuronal cells. J. Cell Sci. 124, 2457-2465. doi: 10.1242/jcs.086470

Tao-Cheng, J. H. (2007). Ultrastructural localization of active zone and synaptic vesicle proteins in a preassembled multi-vesicle transport aggregate. Neuroscience 150, 575-584. doi: 10.1016/j.neuroscience.2007.09.031

Tischfield, M. A., Cederquist, G. Y., Gupta, M. L., and Engle, E. C. (2011). Phenotypic spectrum of the tubulin-related disorders and functional implications of disease-causing mutations. Curr. Opin. Genet. Dev. 21, 286-294. doi: 10.1016/j.gde.2011.01.003

Tortosa, E., Galjart, N., Avila, J., and Sayas, C. L. (2013). MAP1B regulates microtubule dynamics by sequestering EB1/3 in the cytosol of developing neuronal cells. EMBO J. 32, 1293-1306. doi: 10.1038/emboj.2013.76

Vale, R. D. (2003). The molecular motor toolbox for intracellular transport. Cell 112, 467-480. doi: 10.1016/s0092-8674(03)00111-9

van der Vaart, B., van Riel, W. E., Doodhi, H., Kevenaar, J. T., Katrukha, E. A., Gumy, L., et al. (2013). CFEOM1-associated kinesin KIF21A is a cortical microtubule growth inhibitor. Dev. Cell 27, 145-160. doi: 10.1016/j.devcel. 2013.09.010

van Spronsen, M., Mikhaylova, M., Lipka, J., Schlager, M. A., van den Heuvel, D. J., Kuijpers, M., et al. (2013). TRAK/Milton motor-adaptor proteins steer mitochondrial trafficking to axons and dendrites. Neuron 77, 485-502. doi: 10. 1016/j.neuron.2012.11.027

Vaughn, J. E. (1989). Fine structure of synaptogenesis in the vertebrate central nervous system. Synapse 3, 255-285. doi: 10.1002/syn.890030312

Verhey, K. J., and Hammond, J. W. (2009). Traffic control: regulation of kinesin motors. Nat. Rev. Mol. Cell Biol. 10, 765-777. doi: 10.1038/nrm2782

Verhey, K. J., Lizotte, D. L., Abramson, T., Barenboim, L., Schnapp, B. J., and Rapoport, T. A. (1998). Light chain-dependent regulation of kinesin's interaction with microtubules. J. Cell Biol. 143, 1053-1066. doi: 10.1083/jcb. 143.4.1053

Vershinin, M., Carter, B. C., Razafsky, D. S., King, S. J., and Gross, S. P. (2007). Multiple-motor based transport and its regulation by tau. Proc. Natl. Acad. Sci. U S A 104, 87-92. doi: 10.1073/pnas.0607919104

Vitriol, E. A., and Zheng, J. Q. (2012). Growth cone travel in space and time: the cellular ensemble of cytoskeleton, adhesion and membrane. Neuron 73 , 1068-1081. doi: 10.1016/j.neuron.2012.03.005

Wagh, D., Terry-Lorenzo, R., Waites, C. L., Leal-Ortiz, S. A., Maas, C., Reimer, R. J., et al. (2015). Piccolo directs activity dependent F-actin assembly from presynaptic active zones via daam1. PLoS One 10:e0120093. doi: 10. 1371/journal.pone.0120093

Waites, C. L., Leal-Ortiz, S. A., Andlauer, T. F., Sigrist, S. J., and Garner, C. C. (2011). Piccolo regulates the dynamic assembly of presynaptic F-actin J. Neurosci. 31, 14250-14263. doi: 10.1523/jneurosci.1835-11.2011

Watanabe, K., Al-Bassam, S., Miyazaki, Y., Wandless, T. J., Webster, P., and Arnold, D. B. (2012). Networks of polarized actin filaments in the axon initial 
segment provide a mechanism for sorting axonal and dendritic proteins. Cell Rep. 2, 1546-1553. doi: 10.1016/j.celrep.2012.11.015

Winckler, B., Forscher, P., and Mellman, I. (1999). A diffusion barrier maintains distribution of membrane proteins in polarized neurons. Nature 397, 698-701.

Witte, H., and Bradke, F. (2008). The role of the cytoskeleton during neuronal polarization. Curr. Opin. Neurobiol. 18, 479-487. doi: 10.1016/j.conb.2008. 09.019

Wolf, M., Zimmermann, A. M., Görlich, A., Gurniak, C. B., Sassoè-Pognetto, M., Friauf, E., et al. (2014). ADF/cofilin controls synaptic actin dynamics and regulates synaptic vesicle mobilization and exocytosis. Cereb. Cortex doi: 10. 1093/cercor/bhu081 [Epub ahead of print].

Wong, M. Y., Zhou, C., Shakiryanova, D., Lloyd, T. E., Deitcher, D. L., and Levitan, E. S. (2012). Neuropeptide delivery to synapses by long-range vesicle circulation and sporadic capture. Cell 148, 1029-1038. doi: 10.1016/j.cell.2011. 12.036

Wortman, J. C., Shrestha, U. M., Barry, D. M., Garcia, M. L., Gross, S. P., and Yu, C. C. (2014). Axonal transport: how high microtubule density can compensate for boundary effects in small-caliber axons. Biophys. J. 106, 813-823. doi: 10. 1016/j.bpj.2013.12.047

Wu, Y. E., Huo, L., Maeder, C. I., Feng, W., and Shen, K. (2013). The balance between capture and dissociation of presynaptic proteins controls the spatial distribution of synapses. Neuron 78, 994-1011. doi: 10.1016/j.neuron.2013. 04.035

Xu, K., Zhong, G., and Zhuang, X. (2013). Actin, spectrin and associated proteins form a periodic cytoskeletal structure in axons. Science 339, 452-456. doi: 10. 1126/science. 1232251

Yamada, K., Andrews, C., Chan, W. M., McKeown, C. A., Magli, A., de Berardinis, T., et al. (2003). Heterozygous mutations of the kinesinKIF21A in congenital fibrosis of the extraocular muscles type 1 (CFEOM1). Nat. Genet. 35, 318-321. doi: $10.1038 /$ ng1261

Yamada, K. H., Hanada, T., and Chishti, A. H. (2007). The effector domain of human Dlg tumor suppressor acts as a switch that relieves autoinhibition of kinesin-3 motor GAKIN/KIF13B. Biochemistry 46, 10039-10045. doi: 10. 1021/bi701169w

Yoshimura, T., and Rasband, M. N. (2014). Axon initial segments: diverse and dynamic neuronal compartments. Curr. Opin. Neurobiol. 27, 96-102. doi: 10. 1016/j.conb.2014.03.004

Yuan, A., Rao, M. V., Veeranna, and Nixon, R. A. (2012). Neurofilaments at a glance. J. Cell Sci. 125, 3257-3263. doi: 10.1242/jcs.104729

Zhang W., and Benson, D. L. (2001). Stages of synapse development defined by dependence on F-actin. J. Neurosci. 21, 5169-5181. doi: 10.1016/00928674(94)90012-4

Zempel, H., and Mandelkow, E. (2014). Lost after translation: missorting of Tau protein and consequences for alzheimer disease. Trends Neurosci. 37, 721-732. doi: 10.1016/j.tins.2014.08.004

Conflict of Interest Statement: The authors declare that the research was conducted in the absence of any commercial or financial relationships that could be construed as a potential conflict of interest.

Copyright (c) 2015 Kevenaar and Hoogenraad. This is an open-access article distributed under the terms of the Creative Commons Attribution License (CC BY). The use, distribution and reproduction in other forums is permitted, provided the original author(s) or licensor are credited and that the original publication in this journal is cited, in accordance with accepted academic practice. No use, distribution or reproduction is permitted which does not comply with these terms. 